\title{
Levels of Agricultural Pesticides in Sediments and Irrigation Water from Tono and Vea in the Upper East of Ghana
}

\author{
Kenneth B. Pelig-Ba \\ Faculty of Applied Sciences, University for Development Studies, Navrongo, Ghana. \\ Email: kbpeligba@yahoo.com \\ Received April $7^{\text {th }}, 2011$; revised May 15 th 2011 ; accepted June $19^{\text {th }}, 2011$.
}

\begin{abstract}
Water and sediment samples were taken from selected irrigation dams located at Tono and Vea in the Upper East Region of Ghana and analyzed for organic pesticides using gas chromatography. Sixteen organic residues were identified of which thirteen had at least some trace concentrations ranging from 0.001 to $25.4 \mu \mathrm{g} / \mathrm{L}$. It was found in the laboratory that the concentrations of DDT, BHC and heptachlor were above the upper limited recommended by WHO and the concentrations of DDT in both reservoirs were higher than 20 times the recommended limits. High concentrations of $D D T$ were found in the water samples while the other two residues were identified in the sediments. The high DDT concentration in water was due to 1) the initial amount of DDT applied and the period in the reservoirs, 2) a half-life of 350 days suggested that much of the DDT originally used was not destroyed if applied less than this period, 3) its low solubility in water did not allow for dissolution and subsequent dispersal in water; 4) the indiscriminate uses of DDT for fishing as confirmed by the local people The high DDT level suggested that the water is not safe for many aquatic organisms and even humans. Generally the levels of these organic residues suggested that the dams have been polluted due to human activities such as farming and the unorthodox method of fishing. Therefore, steps should be taken to reduce the levels of DDT concentrations to preserve the aquatic life in the dams.
\end{abstract}

Keywords: Pesticides, Sediments, Irrigation Dams, Tono, Vea

\section{Introduction}

Various attempts to increase yield in agriculture, horticulture or forestry have been a preoccupation of mankind to reduce poverty and eliminate hunger in the world at large and developing countries in particular. This has resulted in the effort to protect especially food crops from being destroyed by insects and pests. Consequently, it has led to the adoption of various crop protection measures particularly the use of synthetic chemicals such as pesticides. As a result of the ease in which these chemicals eliminate their prey, most crop scientists have adopted it as the saviour or the best way to reduce their burden on the search for more appropriate, reliable, fast and safer method of protection. Uses of these pesticides have not only been extensive but also indiscriminate thus creating problems in soil and water pollution. Since the mode of application is sometimes not done according to right prescriptions, pesticides can either miss their target points or get drifted to other areas where they are not required. Furthermore, the methods of applying these chemicals also affect the target organisms. Frequent and indiscriminate use of these chemicals have resulted in the development of pesticide resistant insects, destruction of beneficial organisms, rapid resurgence of target pest population following treatment, uncontrolled outbreak of secondary pest, undesirable environmental effects causing socio-economic problems and high mortality rate to non-target organisms, including man [1]. Since the introduction of these pesticides, farmers in Ghana and for that matter, the Upper East Region in one way or the other have participated in some of the indiscriminate uses of these hazardous chemicals in the environment either for the control of pests or in an attempt to improve the fertility of soils. Another reason for indiscriminate application is an attempt to provide needed protein sources such as fish resulting in the use of these chemicals in some water bodies. However, if these chemicals were efficiently used, there would be minimal effect on the 
environment, but due to the ignorance and lack of education on the right uses of these pesticides in many cases, this has not been the case. It was in this light that this study was undertaken to assess the level of organic-derived pollutants in water and sediments in two selected irrigation dams in the Upper East Region of Ghana and the possible health impact on the local people who continue to consume fish and crop products from these dams.

\section{Location}

The study was limited to water and sediments from Tono and Vea irrigation dams in the Kassena-Nankana and Bolgatanga Districts respectively, of the Upper East Region of Ghana. Tono is located on latitude $10^{\circ} 60^{\prime} \mathrm{N}$ and longitude $1^{\circ} 07^{\prime} \mathrm{W}$ while Vea is on latitude $10^{\circ} 45^{\prime} \mathrm{N}$ and longitude $1^{\circ} \mathrm{W}$ (Figure 1). The vegetation in the study area is dry guinea savannah characterized by short grasses and fire-resistant trees. The climate is sub-Sahelian, with mean minimum and maximum temperatures of 14 and $40^{\circ} \mathrm{C}$, respectively.

The mean annual rainfall ranges from 850 to $1000 \mathrm{~mm}$ which occurs in the months of May-October, followed by a prolonged dry season. The first part of the dry season from November to mid February is characteristically cold and dry with dusty harmattan winds. The rest of the dry season is usually characterized by a wide temperature range from $14^{\circ} \mathrm{C}$ at night and to over $35^{\circ} \mathrm{C}$ during the day. Humidity is also very low making the daytime temperature high and less comfortable [2]. The water reservoirs of both dams are man-made. The Vea project serves eight villages with a total farmer population of 6000 whiles the Tono project serves three villages. The maximum surface area of Vea reservoir is 405 ha with a maximum storage of $1.7 \times 10^{7} \mathrm{~m}^{3}$ serving $21 \mathrm{~km}$ of main canals. The Tono reservoir has a size of 16 ha and a maximum storage of about $5.0 \times 10^{5} \mathrm{~m}^{3}$. The irrigation projects were constructed to provide water for livestock and to facilitate dry season farming. Farmers at these sites combine rudimentary tools with modern equipment and fertilizers to increase yield. The main types of farming adopted in these irrigation sites are mono and mixed cropping which are all at subsistence level. Fishing in these dams is officially allowed under controlled and limited scale.

\section{Literature Review}

Pollution has been defined as introduction by man into the environment of substances or energy liable to cause hazards to human health, harm to living resources and ecological systems, damage to structures or amenity, or interference with legitimate uses of the environment [3]. The media that could be polluted are air, land and water. Any substance that disallows the normal use of water or air is regarded as a pollutant. Pollutants can either be inorganic or organic. Inorganic pollutants are derived from compounds of inorganic substances while those from organic are from hydrocarbons and their derivatives.

Organic pollution was first manifested following the increase in the use of pesticides in the years immediately

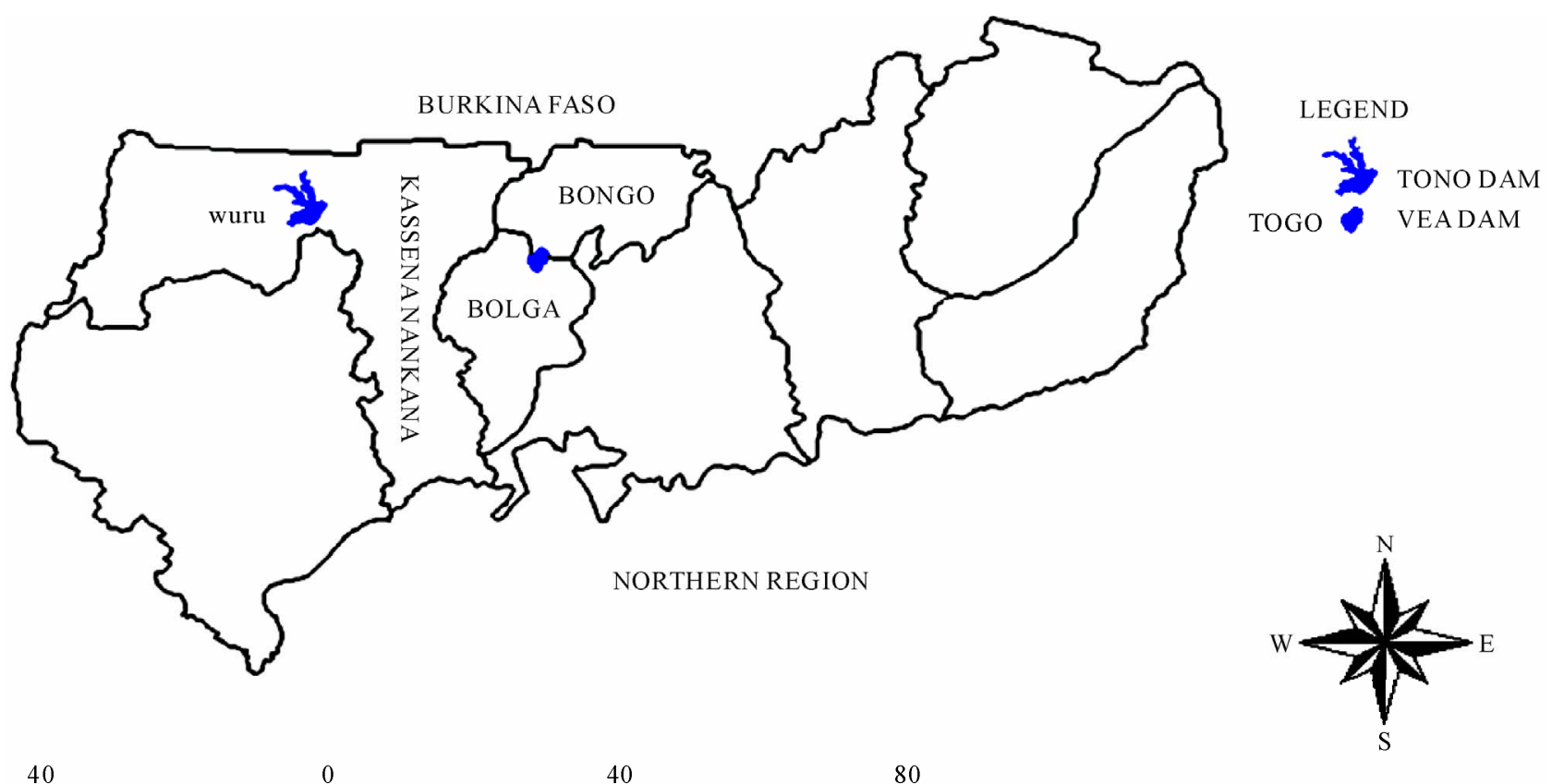

Figure 1. Location of Tono and Vea dams in the upper east region of Ghana. 
after the Second World War. The first organochlorine pesticides to be produced were DDT, Lindane and Dieldrin. Over the period 1950-1970 the number of individual pesticides increased from about 20 to 140 types while the number of insecticides rose from 40 to 170 types [4].

Chemical organic pollutants are toxic substances that are synthesized, or are by-products of combustion or industrial processes. These organic pollutants are characterized by their chemical properties such as toxicity and persistence. As a result of their persistence, they remain in the environment for a long time before degrading and are normally termed Persistence Organic Pollutants (POPs). This property makes them to be transported to long distances by wind or water before being deposited. The effects on human health due to exposure to these pollutants vary according to the type, level and length of the exposure. Well known POPs include dioxin, polychlorinated biphenyls (PCBs), and dichlorodiphenyltrichloroethane (DDT). Many developed nations have banned the use of many of these pollutants as their persistence in the environment has been known for many years and many alternatives are now available. The health of fish and other organisms in an aquatic environment is influenced by the complex interplay of physicochemical factors. Some of these factors are temperature, $\mathrm{pH}$, electrical conductivity and total dissolved solids (TDS). It was observed that the optimum surface temperature in the tropics favourable for fish growth occurred in the range from $23^{\circ} \mathrm{C}$ to $28^{\circ} \mathrm{C}$ [5]. This work was supported by others and they [6] also suggested that the optimum temperature range favourable for the growth of fish is between $20^{\circ} \mathrm{C}$ and $30^{\circ} \mathrm{C}$. Other studies revealed that, the desirable $\mathrm{pH}$ range for fish production is 6.5 $9.0[7,8]$. It further suggested that, the optimum water $\mathrm{pH}$ for culturing is from neutral to slightly alkaline $7.0-8.0$ [5]. It was however, stated by [9] that, excessively low or high $\mathrm{pH}$ is detrimental to fish production in the tropics. Slow growth results from $\mathrm{pH}$ level below the range of 6.0 6.5. Acid death point is reported to be below $\mathrm{pH} 4.0$ whilst the alkaline death point $\mathrm{pH}$ is above 11.0.

Rainfall which is the main source of water into surface water is considered acidic if the $\mathrm{pH}$ falls below 5.6, the normal equilibration value of carbon dioxide and water at $25^{\circ} \mathrm{C}$ [10]. Airborne material probably contributes to the increase in the $\mathrm{pH}$ of subsequent rainfall [11]. The impact of acidity due to decrease in $\mathrm{pH}$ of rainfall is reduced to a certain degree by the buffering capacity of the area soils. Soil $\mathrm{pH}$ is an important factor for farmers and gardeners for several reasons in that many plants and some microorganisms prefer varied media for their survival. Some diseases tend to thrive well either in alkaline or acidic soils. Also $\mathrm{pH}$ can affect the availability of nutrients in the soil.
Pesticides are used on and around plants either to fight off plant diseases or rid off bugs that feed on or kill them. If the soil $\mathrm{pH}$ is very acidic, the applied pesticides will not be absorbed by the plant but held on to the soil matrix and washed away by water which subsequently run into streams, rivers, lakes, or groundwater where they become pollutants [12]. Application of fertilizers containing ammonium or urea speeds up the rate at which acidity develops. The decomposition of organic matter also adds to soil acidity [13]. Soils contain carbon (C) in both organic and inorganic forms. In most soils, more $\mathrm{C}$ is held as soil organic carbon (SOC). Soil organic matter (SOM) is used to describe the organic constituents in the soil such as tissues from dead plant and animal products obtained decomposing into the soil. Soil organic carbon is important for the functioning of ecosystems and agro-ecosystems, influences the physical structure of the soil, the water holding capacity, its ability to form complexes with metal ions and supply of nutrients. Loss of SOC can therefore, lead to a reduction in soil fertility, land degradation and even desertification [14]. For this study the parameters to be analyzed are $\mathrm{pH}$, electrical conductivity, organic carbon and pesticides of both water and sediments from the two irrigation dams in the study area. Various pesticides have different half-lives which are dependent on the medium in which the chemical is applied. It has been reported for example that the half-life for DDT in the water environment is 56 days in lake water and about 28 days in river water.

\section{Methodology}

\subsection{Selection of Farmer and Individuals}

The study began with the selection and interview of groups of farmers and individuals living around the vicinity of the two dams on the type of chemicals used and other relevant base information required. This work was carried out in November, 2007 to May 2008. Farmers who were known to be fisher men were targeted while individuals from the communities were selected randomly.

\subsection{Collection of Water and Sediment Samples}

Soil and water samples were collected from the two dams at Tono and Vea irrigation sites. A PVC pipe of 101.6 $\mathrm{mm}$ (4 inches) diameter and $508 \mathrm{~mm}$ (20 inches) length was sunk into the soil. The pipe was then removed with the soil material captured and sealed in a polyethylene bag to minimize adsorption and volatilization of analytes during the transit period to the laboratory. Both water and sediment samples were labelled as $\mathrm{T}$ and $\mathrm{V}$ for Tono and Vea respectively. Water samples were collected from a depth of $0.2 \mathrm{~m}$ into a well-cleaned glass of 1.5 litre 
capacity and sealed with double cap device. These samples were filled to the top without leaving any space in order to prevent any release of dissolved gases during the transit period. This was done monthly from January 2008 to May 2008. The $\mathrm{pH}$, conductivity and temperature of the water samples were determined at the sites.

In the laboratory, soil samples were carefully removed from the PVC pipe and its total length recorded. Later, it was sectioned into the various layers and left to dry under laboratory temperature for about 7 days. The airdried samples were then disaggregated, after which $25 \mathrm{~g}$ of each was ground with a porcelain mortar and pestle and sieved through a $2 \mathrm{~mm}$ nylon sieve. The sediments were then labelled accordingly and stored in enclosed containers in a cupboard for analyses.

\subsection{Sample Analyses}

The soil $\mathrm{pH}$ was determined by shaking a sample in a ratio of 1 part soil to 2 parts distilled water. SOC was determined based on the Walkley-Black chromic acid wet oxidation method. About $1.0 \mathrm{~g}$ of fine sediment sample was weighed into a $250 \mathrm{~mL}$ conical flask, followed by $10 \mathrm{~mL}$ of $1 \mathrm{M} \mathrm{K}_{2} \mathrm{Cr}_{2} \mathrm{O}_{7}$ solution, and swirling gently to disperse the particles. Then $20 \mathrm{~mL}$ of concentrated $\mathrm{H}_{2} \mathrm{SO}_{4}$ was added, and further a $100 \mathrm{~mL}$ distilled water added and allowed to stand for 30 minutes. About 3-4 drops of starch indicator was added and titrated against $0.5 \mathrm{M} \mathrm{FeSO}_{4}$, and repeated two times.

Pesticide residues were estimated using international standard methods [15]. One litre of water was put into a separatory funnel and $75 \mathrm{~mL}$ of dichloromethane (DCM) added and shaken for sometime to thoroughly mix the solute and solvents and later allowed to stand to separate out. The lower layer extract (DCM) was then released into an evaporating tube and the upper layer (water) discarded. A drop of iso-octane was added to the extract and the volume reduced to $0.5 \mathrm{~mL}$ and later transferred into another test tube. The extract was conditioned with $4 \mathrm{~mL}$ $(3+1 \mathrm{~mL})$ cyclohexane $(\mathrm{CH})$ : dichloromethane $(\mathrm{DCM})$ mixture followed by $3 \mathrm{~mL} \mathrm{CH}$. With the SPE connected to a test tube, the extract was dropped onto the SPE and eluted with $4 \mathrm{~mL} \mathrm{CH}$. Elution was continued with 4 (3+ 1) $\mathrm{mL} C H: D C M$ mixture and the volume finally reduced to $0.5 \mathrm{~mL}$ and transferred into a $2 \mathrm{~mL}$ sample vial for a gas chromatography run. For sediments, about $10 \mathrm{~g}$ was weighed into a centrifuge glass tube and $50 \mathrm{~mL}$ DCM added. It was shaken vigorously and put in an ultrasonic bath for 15 minutes, then on to a shaker for 60 minutes. It was then centrifuged and the supernatant collected into an evaporating tube and a drop of iso-octane added. The volume was finally reduced to $0.5 \mathrm{~mL}$. This was then transferred into a test tube, rinsed and added to extract and reduced to $0.5 \mathrm{~mL}$. The concentration of the pesti- cide reported in this study, was based upon the lowest concentration that could consistently be reliably recovered ( $>70 \%)$ in the laboratory from fortified samples [16]. If this percent recovery could not be achieved, the most consistent pesticide recovery was used to establish the quantification limit (QL). The QL for all pesticides detected in both water and sediment samples in this study was $0.001 \mu \mathrm{g} / \mathrm{L}$ and $0.001 \mathrm{mg} / \mathrm{kg}$ dry weight respectively.

\section{Results}

\subsection{Basic Information}

The interviews conducted with the farmers and staff of the irrigation companies, revealed that pesticides used by farmers at the irrigation sites include roundup, atrazine, selective endosulfan, kuzitrine and DDT. It was also observed that some natives and fishermen use artificial chemicals such as DDT for fishing. Some of the chemicals are usually applied at night so that by daybreak the fishes would have died and floated for collection. Some of the chemicals were also sprayed on the cultivated crops on farms.

\subsection{Physicochemical Properties of Water and Sediment Samples}

The water temperatures varied monthly from $25.1^{\circ} \mathrm{C}$ to $34.2^{\circ} \mathrm{C}$ for Tono and $24.7^{\circ} \mathrm{C}$ to $29.4^{\circ} \mathrm{C}$ for Vea from January 2008 to May 2008. The $\mathrm{pH}$ values of water obtained during this period varied from 6.6 to 7.2 for Tono and 6.8 to 6.9 for Vea. This is not different for normal surface water. The electrical conductivity of the reservoirs was generally low, less than $30 \mu \mathrm{S} / \mathrm{cm}$ and did not have any overall effect on the quality of the water from both reservoirs. This therefore suggested, that the water in the reservoirs was not mineralized, since it contained low dissolved solids. Water from Vea recorded a TDS value of $106 \mathrm{mg} / \mathrm{L}$, while that of Tono recorded 57.1 $\mathrm{mg} / \mathrm{L}$. These values are low compared to what is normally observed in many surface water systems. Soil $\mathrm{pH}$ values obtained for Tono and Vea ranged from 6.02 to 6.49 and 6.05 to 6.61 respectively for the three layers. In Tono the highest $\mathrm{pH}$ was obtained in the third layer (C) (Table 1) while the second layer in Vea recorded the highest. No marked trend was observed probably because either the sample size was low or that the factors affecting the $\mathrm{pH}$ were not the same in the two reservoirs. However, the soil $\mathrm{pH}$ was generally lower than that of the water in both places.

Soil organic carbon values for the various layers are also indicated in Table 1. The highest SOC was obtained in Vea $(2.89 \%)$ with the site giving relatively higher values than Tono. There was a decrease of SOC from top to 
bottom of the soil profile suggesting that decayed vegetative parts on top are responsible for the high values on the top horizon. Also the higher value of SOC in Vea could be attributed to the higher acidity of the top soil relative to Tono since the destruction of organic matter is facilitated by the acidity of the medium.

\subsection{Levels of Pesticides in Water and Sediments}

A total of 16 pesticides were analyzed of which thirteen were detected in both water and soil sediments. Concentration levels of some of the pesticide residues were below the quantification limit (QL) of $0.001 \mu \mathrm{g} / \mathrm{L}$ in the water and $1.0 \mu \mathrm{g} / \mathrm{L}$ in the sediments. Most of the residue concentrations fell below the WHO (1993) guidelines. However, a few pesticides such as p, p-DDT, were obtained in water at levels of $22.4 \mu \mathrm{g} / \mathrm{L}$ at Tono and 25.4 $\mu \mathrm{g} / \mathrm{L}$ at Vea, while for $\beta$-BHC it was $3 \mu \mathrm{g} / \mathrm{L}$ for Tono and $5 \mu \mathrm{g} / \mathrm{L}$ for Vea in sediments, Heptachlor epoxide level was $1.0 \mu \mathrm{g} / \mathrm{L}$ for sediments in the two places. These were the only pesticides that were higher than the guideline limits. The guideline limit of $\mathrm{p}, \mathrm{p}$-DDT values is $1.00 \mu \mathrm{g} / \mathrm{L}$ while the value for $\beta$-BHC in the sediments is $2 \mu \mathrm{g} / \mathrm{L}$ (Table 2) and that for the heptachlor epoxide is $0.1 \mu \mathrm{g} / \mathrm{L}$. The high value of DDT in the two dams suggested that there is either an increase in use of these chemicals in the two dams or a high drift from surrounding areas.

Although these dams are used for irrigation and watering of animals, fishing goes on and sometimes takes place at odd hours of the day. The possible use of DDT for fishing, as was revealed through the interviews, could explain the high concentration in the dams. It is worth noting that DDT is among the banned chemicals in Ghana.

Furthermore, $\beta$-BHC is also used to dress seeds and any run-off water can wash it into the dam while those

Table 1. Organic carbon and $\mathrm{pH}$ of soil sediment layers at various depths.

\begin{tabular}{ccccccc}
\hline & TONO & TONO & TONO & VEA & VEA & VEA \\
\cline { 2 - 7 } & DEPTH (cm) & S.O.C. (\%) & SOIL $\boldsymbol{p H}$ & DEPTH (cm) & S.O.C. $(\%)$ & SOIL $\boldsymbol{p H}$ \\
\hline LAYER A & 7.00 & 2.31 & 6.32 & 13.72 & 2.89 & 6.05 \\
LAYER B & 16.13 & 0.75 & 6.02 & 25.65 & 1.12 & 6.61 \\
& 34.16 & 0.37 & 6.79 & 46.86 & 0.51 & 6.40 \\
\hline
\end{tabular}

Table 2. Pesticide levels $(\mu \mathrm{g} / \mathrm{L})$ in water and sediment samples.

\begin{tabular}{|c|c|c|c|c|c|}
\hline \multirow{3}{*}{ PARAMETER } & \multicolumn{4}{|c|}{ SAMPLES } & \multirow{3}{*}{ WHO (1993) } \\
\hline & \multicolumn{2}{|c|}{ TONO } & \multicolumn{2}{|c|}{ VEA } & \\
\hline & Water & Sediment & Water & Sediment & \\
\hline Alpha BHC & 0.007 & $<1$ & 0.063 & $<1$ & 2.00 \\
\hline Gamma BHC & 0.006 & $<1$ & 0.035 & $<1$ & 2.00 \\
\hline Beta BHC & 0.050 & 3 & 0.004 & 5 & 2.00 \\
\hline Delta BHC & 0.004 & 1 & 0.004 & 1 & 2.00 \\
\hline Heptachlor & $<0.001$ & $<1$ & 0.009 & $<1$ & 0.10 \\
\hline Aldrin & 0.002 & $<1$ & $<0.001$ & $<1$ & 0.03 \\
\hline Heptachlor Epoxide & $<0.001$ & 1 & $<0.001$ & 1 & 0.10 \\
\hline $\mathrm{p}, \mathrm{p}$ '-DDE & 0.002 & $<1$ & 0.004 & $<1$ & 1.00 \\
\hline Dieldrin & 0.001 & $<1$ & 0.007 & $<1$ & 0.03 \\
\hline Beta Endosulfan & 0.007 & $<1$ & $<0.001$ & $<1$ & 0.03 \\
\hline p,p'-DDD & $<0.001$ & $<1$ & 0.099 & $<1$ & 1.00 \\
\hline Endosulfan Sulphate & $<0.001$ & $<1$ & 0.007 & $<1$ & 0.03 \\
\hline $\mathrm{p}, \mathrm{p}-\mathrm{DDT}$ & 22.4 & $<1$ & 25.4 & $<1$ & 1.00 \\
\hline
\end{tabular}


that are applied to protect the vegetative cover against flying insects and pests can also be blown by wind into the dam water. Comparatively high $\beta$-BHC was obtained in the soils than the water. The levels of $\delta$-BHC and heptachlor epoxide were similar in the two dam sites. This may be because adsorption on sediments causes the biodegradation of the pesticides easily since biodegradation of organic residues can be enhanced by both temperature and microorganisms in the soil. This may not be possible with water where the pesticides are not soluble and can be maintained for a long period.

\subsection{Comparison of Pesticide Levels in Vea and Tono Dams}

Among the 16 pesticides detected in the water samples from the two dams, 9 were found in Vea and 8 in Tono. These are all represented in Figure 2 except DDT. High DDT was found in both places but, Vea recorded a higher value of $25.4 \mu \mathrm{g} / \mathrm{L}$ than Tono, which had a value of $22.4 \mu \mathrm{g} / \mathrm{L}$. These values were far higher than the other residues and could not therefore be represented in the figure. From Figure 2, it is observed that heptachlor epoxide and p,p-DDD were not detected in the water samples from Tono but were significant in the Vea dam samples. Similarly, Aldrin was detected in the Tono but could not be seen in the Vea samples. In fact, p,p-DDD recorded the highest level among the pesticides presented and was found in Vea. $\beta$-BHC was highest in the Tono dam but very low in the Vea dam. The $\alpha$-BHC and $\gamma$-BHC were higher in Vea as compared to that in Tono dam. Figure 2 shows that pesticide residues generally were higher in the water samples in Vea than Tono.

\section{Discussion of results}

\subsection{Physicochemical Characteristics}

Physicochemical parameters analyzed for the water showed generally good conditions for the growth, development and survival of aquatic life especially fish in the reservoirs. The temperature values were within that suggested by [6] and [5] indicating that fish production could be favoured in these reservoirs. This is confirmed by the regular fishing in the dams. The people do not use prescribed methods for fishing but resort to the use of chemicals such as pesticides without recourse to the damage to the environment or their health. Water $\mathrm{pH}$ values were within that obtained by [7] as well as [5] and [9] for fish production. The $\mathrm{pH}$ obtained was not above the optimum $\mathrm{pH}$ conditions for fish production but favours spawning.

\subsection{Pesticides}

The half-lives of DDT, $\beta$-BHC and heptachlor epoxide to be respectively were estimated by [17] to be 8,1 and 3 years in soil. Also [18] found the half-life of DDT to be 15 years in soil, 350 days in surface waters and 31 years in groundwater. The detection of high levels of $p, p-D D T$ in the water samples from both reservoirs suggested that DDT might have been used within a certain short period of time. But in the soils, the level was lower even though the half life is longer than in water suggesting a preferential use of the chemical in each of the environmental systems. Hence high DDT in both reservoirs can be attributed to 1) the initial amount of DDT applied and the period within which it entered into the reservoirs; 2) a halflife of 350 days suggested that much of the DDT originally used was not destroyed, if applied less than this period, 3) its low solubility in water may not allow for dissolution and subsequent dispersal in water; 4) the indiscriminate uses of DDT for fishing as confirmed from the local people could account for high level of DDT. Since DDT is officially banned, it is less likely that application would have been deliberate.

The half-life of BHC and heptachlor epoxide suggests that they were also applied within a short period before the study or that they have been accumulating in the environment. BHC is normally used for spraying crops and dressing seeds against insect attack. Its high level in sediments was due to the application on either water bodies which settle onto the sediment or transported from sprayed crops during the farming period. Due to the acidic nature of the soils, pesticides are loosely adsorbed to soil particles and surface runoff washes away most of the applied pesticides to any nearby water body. Considerable levels of other pesticides were observed in especially the water bodies suggesting that these might have been applied in not a very distant time considering the fact that the half-life in water is usually less than in soil.

\subsection{Health Implications of Pesticides}

Most pesticides have overall polarity and tend not to be washed away by rain. Some are fat soluble and are partitioned between fatty tissues and blood when food containing them is eaten. The pesticides p,p-DDT BHC and heptachlor epoxide have negative health implications that has led to the ban on their use. Generally DDT is not very toxic to humans but its $\mathrm{LD}_{50}$ in rats is $110 \mathrm{mg} / \mathrm{kg}$ [19]. It has been shown that a human test population group ingested $35 \mathrm{mg}$ daily for an extended period without any ill effects but its fatal dose is estimated to be 500 $\mathrm{mg} / \mathrm{kg}$ for humans [19]. Frequent use of DDT and other pesticides can lead to resistance of some organisms in water bodies where it is applied and therefore render it useless when required for the purpose of eradication of insects. It is possible that some fish will take and biomagnify it. It has been shown that some fish such as the 

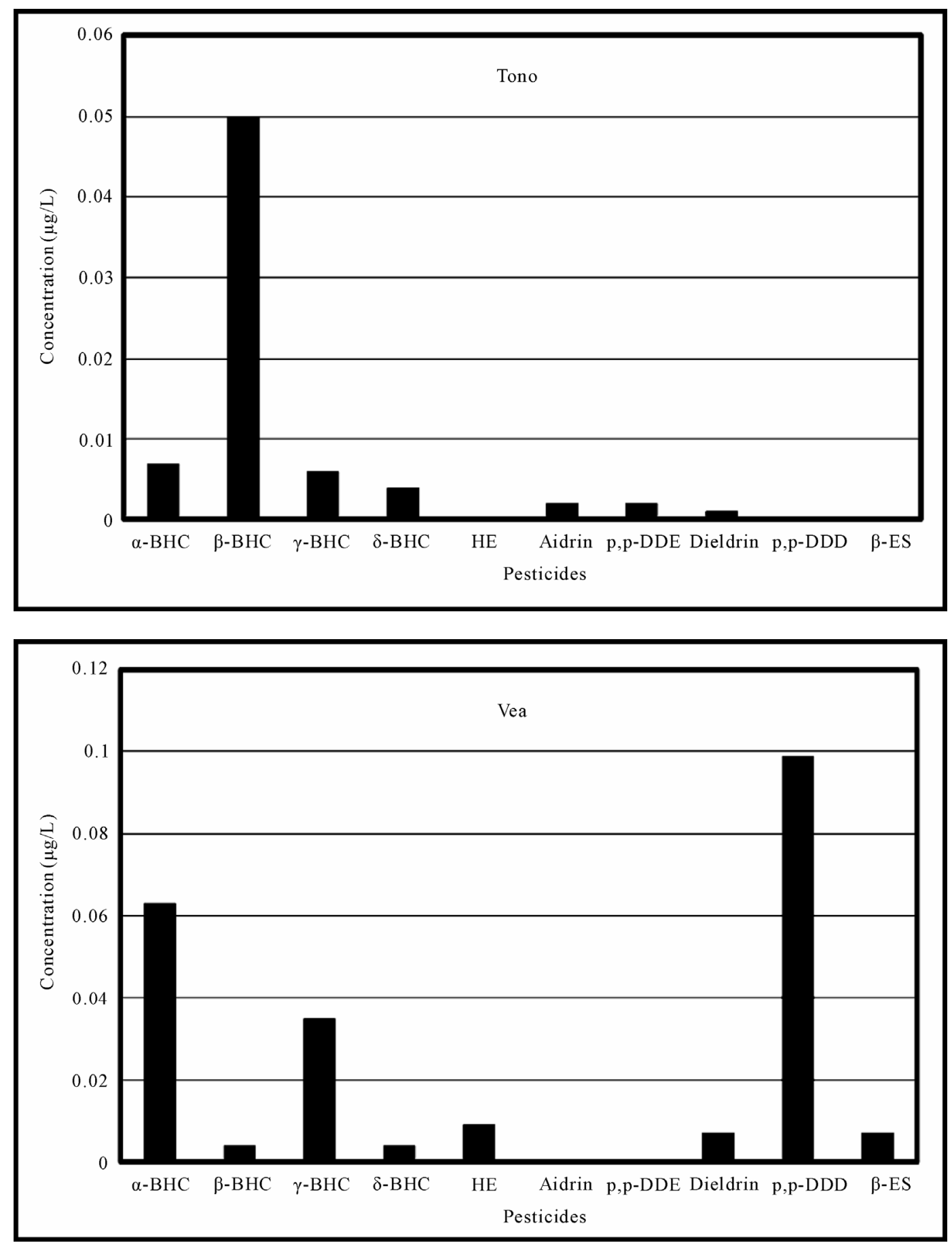

Figure 2. Plot of pesticide levels at Tono and Vea dams. (HE-Heptachlor epoxide, ES-Endosulphan).

rainbow trout has an $\mathrm{LD}_{50}$ for 96 hours is $7 \mu \mathrm{g} / \mathrm{L}$ and it is also extremely toxic for cold blooded creatures. DDT affects the reproduction of higher animals. Because of the lipophilic properties of DDT and its breakdown products, it tends to be accumulated in food chains and in the environment. It has therefore been replaced by non-persistent insecticides. It is moderately toxic to birds, fish and aquatic life. It is resistant to degradation, has widespread persistence in the environment, and high potential for bioaccumulation; this work concludes that DDT and its metabolites should be regarded as a major hazard to the environment. In rats, following oral administration, DDT is metabolized to DDE, DDD and DDA among others. It accumulates in fatty tissues of 
mammals and is excreted in milk. $\mathrm{DT}_{50}$ in tropical regions is about 3 months; in temperate regions, $\mathrm{DT}_{50}$ is 4 30 years. People depending on these reservoir waters are at risk of nerve poisoning and reproduction disorders. It is accumulated in food chains within the environment, fatty tissues of mammals and milk. However, dieldrin is more toxic to fish than aldrin. For example, the $\mathrm{LD}_{50}$ for striped mullet for aldrin is about $100 \mu \mathrm{g} / \mathrm{L}$ while that for dieldrin is $23 \mu \mathrm{g} / \mathrm{L}$ [19].

\section{Conclusions}

Of the 16 pesticides tested, only 3 were at higher levels than recommended guideline values. These were DDT, BHC and heptachlor epoxide. This was attributed to the frequent uses of these particular chemicals for activities such as fishing. DDT concentration was found to be highest and this was explained by 1) the initial high amount of DDT applied and the short period of stay in the reservoirs; 2) a short half-life of 350 days suggested that much of the DDT originally used was not destroyed if applied less than a year before the study and 3) its low solubility in water may not allow for dissolution and subsequent dispersal in water; 4) the indiscriminate use of DDT for fishing as confirmed from the interviews of the local people.

\section{Acknowledgements}

This work could not have been possible without the efforts of Mr. Alex Siaw who did the sampling and analysis.

\section{REFERENCES}

[1] V. Chaudhary, "Environmental Protection," Pointer Publishers, Rajasthan, 2000, pp. 176-183.

[2] M. A. Appawu, S. K. Dadzie, A. Baffoe-Wilmot and M. D. Wilson, "Lymphatic Filariasis in Ghana: Entomological Investigation of Transmission Dynamics and Intensity in Communities Served by Irrigation Systems in the Upper East Region of Ghana Tropical," Medicine \& International Health, Vol. 6, No. 7, 2001, pp. 511-516.

[3] M. W. Holdgate, "A Perspective of Environmental Pollution," Cambridge University Press, Cambridge, 1979.

[4] G. R. Conway and J. N. Petty, "Unwelcome Harvest: Agriculture and Pollution," In: Environmental Protection Agency, Acid Rain, Earthscan, London, EPA-600/9-79036, Office of Research and Development, Washington DC, 1991.
[5] M. Huet, "Textbook of Fish Culture: Breeding and Cultivation of Fish," Second Edition, Ch. De. Wyngaent, Brussels, 1970.

[6] D. R. Smith, "Aquaculture Training Manual," 2nd Edition, Type Sector Limited, Hong Kong, 1993, pp. 12-13.

[7] D. R. Blakely and T. C. Hrusa, "Inland Aquaculture Development Handbook," Fish News Book, 1989, 184 Pages.

[8] E. K. Abban, P. K. Ofori and C.A. Biney, "Fisheries and Aquaculture Development. Assessment of impoundment in West Gonja District, Northern Region," IAB Technical Report, 1994, pp. 36-75.

[9] T. V. R. Pillay, "Aquaculture and the Environment," Type Sector Limited, Hong Kong, 1992, 67 Pages.

[10] G. E. Likens, R. F. Wright, J. N. Galloway and T. J. Butler, “Acid Rain,” Scientific American, Vol. 241, 1979, pp. 43-51. doi:10.1038/scientificamerican1079-43

[11] E. Kessler, S. Fredrickson and P. J. Wigington, Paper at 72nd Annual Meeting, Oklahoma Acad. Sci., Tulsa, OK. 1983.

[12] C. Spector, "Nutrient Manager: Focus on pH and Lime," In: The Handbook of Soils and Climate in Agriculture, University of Maryland's Cooperative Extension Service and Department of Agronomy, LaMotte Company, 2001.

[13] C. J. Smith, M. B. Peoples, G. Keerthisinghe and T. R. James, "Effect of Surface Applications of Lime, Gypsum and Phosphogypsum on the Alleviating of Surface and Subsurface Acidity in a Soil under Pasture," Australian Journal of Soil Research, Vol. 32, No. 5, 1994, pp. 9951008. doi:10.1071/SR9940995

[14] N. H. Batjes, "Total Carbon and Nitrogen in Soils of the World," European Journal of Soil Science, Vol. 47, No. 2, 1996, pp. 151-163. doi:10.1111/j.1365-2389.1996.tb01386.x

[15] T. G. Scholtz and D. A. Flory, "Clearing up the Confusion," Environment Protection, Vol. 10, 1999, pp. 37-41.

[16] WHO, "Guidelines for Drinking Water Quality," 2nd Edition, Vol. 1, 1993, Geneva.

[17] C. A. I. Goring and J. W. Hamaker, "Organic Chemicals in the Soil Environment," Dekker, New York, 1972.

[18] P. H. Howardm, "Handbook of Environnemental Fate and Exposure Data for Organic Chemicals, Vol. III, Pesticides," Lewis Publishers, Chelsea, Michigan, 1991, p. 684.

[19] B. J. Alloway and D. C. Ayres, "Chemical Principles of Environmental Pollution," 2nd Edition, Blackwell Academic \& Professional, London, 1997. 